\title{
Higher education, norm development, and environmental protection
}

\author{
Niklas Harring ${ }^{1}$ (D) $\cdot$ Sverker C. Jagers $^{1} \cdot$ Simon Matti $^{2}$
}

Published online: 21 June 2019

(C) The Author(s) 2019

\begin{abstract}
There is a debate on whether higher education in the social sciences generates stronger democratic and environmental norms among students. In our study, we focus on students' perceptions about legitimate rule in the case of environmental protection. We contribute to this debate by using a unique longitudinal data set from seven universities and university colleges in Sweden. Our results show that higher education in the social sciences does not generate stronger democratic or environmental norms, at least not in the case of environmental protection. We discuss why this is the case and refine our results further by looking at individual-level factors, such as gender and ideology.
\end{abstract}

Keywords Higher education · Sustainable development · Values $\cdot$ Norms $\cdot$ Policy support

\section{Introduction}

To what extent, and by which mechanisms, is higher education a factor behind increasing public support for environmental policy instruments? It is suggested that education in general (e.g., United Nations 2005) and higher education in specific (e.g., Cotton and Alcock 2013; McCowan 2012) are potentially important factors in amending problems of sustainability. However, research has also questioned whether higher education per se can shape environmental norms (e.g., Shephard et al. 2015). This article aims to further our understanding about

Niklas Harring

niklas.harring@pol.gu.se

Sverker C. Jagers

sverker.jagers@pol.gu.se

Simon Matti

simon.matti@ltu.se

1 Centre for Collective Action Research (CeCAR), Department of Political Science, University of Gothenburg, Sprängkullsgatan 19, 40530 Gothenburg, Sweden

2 Political Science Unit, Luleå University of Technology, 97187 Luleå, Sweden 
the relationship between (higher) education and one specific driver of sustainability: public support for environmental policy instruments.

Changed behavioral patterns, altered consumption habits, and reduced ecological footprints including on the individual level are commonly described as necessary for reaching environmental policy goals. However, voluntary behavioral change is not always easily (or at all) accomplished, as most environmental problems can be described as collective action problems, where rational actors' failure to cooperate around a common benefit leads to results that are societally suboptimal (e.g., Olson 1965; Hardin 1968). These problems are especially tangible for large-scale, free-access goods such as natural resources and the common environment. Addressing environmental sustainability thus requires some form of intentional, third-party coordination or, using the terminology of Mansbridge (2014), governmental coercion both to correct the market failures underpinning collective action problems and to handle their consequences. On the national level, these governmental interventions take the form of policy instruments, for example, legislation, taxes, subsidies, and informative measures, targeting and changing unsustainable behavioral patterns.

For democratic systems in particular, a palpable need exists for public support to make such coercive measures feasible. There are several reasons for this. First, as suggested by the higher-order legitimacy problem (cf. Matti 2009), unless a majority of the public supports a proposed policy, it is less likely that democratically elected decision makers will risk stirring up public opinion by trying to implement it (cf. Soroka and Wlezien 2010; Wallner 2008). Second, policy effectiveness and efficiency might be compromised by extensive opposition among the citizenry. Policy support reduces the government's cost for monitoring and enforcing compliance, as those affected by the policies will refrain from attempts to cheat or free-ride to a greater extent (March and Olsen 2004; Beetham 1991). On the other hand, if people find that the formal rules set up for enforcing cooperation are inappropriate, unjust, or disproportional, the cost for monitoring will rise rapidly, making it increasingly difficult for the state to maintain collective action behavior (Ostrom 2005).

As such, a range of studies have examined the conditions under which individuals lend their support to environmental policy instruments. Whereas many focus on the structural conditions that lead to the introduction of third-party coercion, as well as how political and cultural contexts shape cross-national differences in this respect, implicit in these macro-level theories are questions about which factors motivate single individuals to view coercive measures as favorable. Several frameworks and theories focus on the predictors of policy support: for example, perceptions of personal costs and benefits resulting from policy implementation (e.g., Lubell et al. 2007), or different elements of the cognitive system such as ideological positioning, value-orientations, beliefs, and personal norms (Stern et al. 1993; Steg and Vlek 2009). Furthermore, previous research also suggests that individuals' policy attitudes vary depending on a large number of demographic and socio-economic variables, including social background, living conditions, gender, and income (Dunlap et al. 2001).

Another often highlighted factor in the (political-sociology) literature is education, where some studies assert that the higher the level of education, the more likely is the adoption of proenvironmental behaviors as well as higher support for environmental policy instruments (e.g., Van Liere and Dunlap 1980). However, scrutinizing the research on education, the conclusions on the effect of higher education on pro-environmental attitudes and behavior are inconsistent. Furthermore, the link between higher education and policy support could operate through several different mechanisms, affecting either views on environmental protection or on governmental coercion in general. A significant amount of the literature suggests that 
knowledge attained through studies in the social sciences makes students more reflective and facilitates the development of civic norms, for example, trust in the democratic system and in fellow citizens, since they are taught the value of such norms (Brady et al. 1995; Brand 2010; Bryant et al. 2012; Dee 2004; Galston 2001; Lewis-Beck et al. 2009; Milligan et al. 2004; Nie et al. 1996; Pascarella and Terenzini 1991; Paterson 2009; Persson 2013; Stubager 2008; Van de Werfhorst and de Graaf 2004). A direct link between higher education and environmental values in particular has also been claimed (Vaske et al. 2001). These results might help us understand why people with higher education also tend to be more supportive of environmental policy measures: first, since stronger civic norms might increase the acceptance of authoritative decision-making in general, and, second, since higher education might lead to the development of pro-environmental norms more specifically.

In this paper, we hypothesize a direct effect of higher education on policy support. However, we also attempt to reveal the causal mechanisms between these two variables. In these endeavors, we develop additional hypotheses. First, we derive a model suggesting that higher education generates stronger pro-environmental norms that eventually have positive effects on people's propensity to support policies. Thereafter, we develop another hypothesis suggesting an alternative causality: Education gives rise to reinforced civic norms, leading to increased support for political steering in general, which in turn generates more support for environmental policy measures. To investigate this, we analyze a unique (three-step) panel survey data set distributed to university students at seven different universities in Sweden $(N=$ 1801, first-wave), using structural equation modeling.

In the next section, we theorize on the relationship between education and support for environmental policy measures and derive hypotheses to be empirically tested. Thereafter, we introduce our data, discuss our dependent and independent variables, and account for the various statistical techniques used to test our models. We conclude with a concise results section, a discussion of our results, and a section where we present our conclusions and their practical implications for both measures of governmental coercion and further research on higher education as a driver for environmental policy support.

\section{Education and environmental policy support}

A number of previous studies have found that education constitutes a factor that is significantly and positively correlated with various pro-environmental attitudes, including policy support (Cotton and Alcock 2013; Kvaløy et al. 2012; O’Connor et al. 1999; Zahran et al. 2006; Van Liere and Dunlap 1980; Jones and Dunlap 1992). Thus, as a first hypothesis, we propose:

\section{H1: There is a direct effect of higher education on environmental policy support.}

However, evidence for the positive effect of higher education on environmental attitudes in general is both challenged (e.g., Shephard et al. 2015) and lacking empirically founded inferences on the mechanisms by which this effect may take place. In what follows, we test two alternative routes by which higher education, through shaping different sets of personal norms, impacts individuals' levels of environmental policy support. First, we test whether higher education affects environmental policy support through a set of environmental norms, determining the level of environmental concern and, in particular, the extent to which individuals become aware of their own responsibility for the negative effects of environmental 
degradation and their ability to amend it. Second, we explore whether the effect of higher education on policy support is a function of civic norms, which in turn determine attitudes both towards political steering more generally and, subsequently, towards the manifestation of such steering in the form of specific policy measures.

\section{Higher education and environmental norms}

Although concern for the environment might well be founded in self-interest based costbenefit calculations (e.g., Sagoff 1988), a growing body of evidence indicates that for issues closely related to collective interests, moral-normative concerns play an even more significant role in guiding attitude formation and contribute significantly to explaining low-cost behaviors such as policy support (Steg and Vlek 2009; De Groot and Steg 2008). Using Schwartz's (1977) norm-activation model as a point of departure, a wide range of studies demonstrate how pro-social or environmental values (e.g., Jagers and Matti 2010, Jagers et al. 2014; Nordlund and Garvill 2002) and general environmental beliefs (Dunlap et al. 2000) cause the individual to become aware of the negative consequences of a certain situation as well as to ascribe personal responsibility for creating, and therefore preventing, these consequences. This chain of factors subsequently leads the individual to develop personal norms to undertake various pro-environmental actions and to support policy measures to this effect (Stern et al. 1995). Whether higher education actually shapes pro-environmental norms is debatable. There are mixed results, and potentially, it depends on whether higher education focuses not only on cognitive skills but also on affective outcomes (Shephard 2008; Arnon et al. 2015). Yet, studies have shown a relationship between education and environmental norms (Vaske et al. 2001; see also Inglehart 1990), and other studies, using longitudinal data, have shown that years of higher education do not shape environmental norms (e.g., Harraway et al. 2012; Shephard et al. 2015). However, our second hypothesis proposes that the effect of higher education on policy support is channeled through the development (or transformation) of pro-environmental norms.

\section{H2: Higher education affects environmental policy support indirectly through pro- environmental norms.}

\section{The significance of civic norms}

Simultaneously, attitudes towards specific environmental policy measures might be less connected to specific preferences for environmental protection and instead be the result of more general attitudes towards the relationship between the governor and the governed, such as the legitimacy of democratic governments' rights to make authoritative decisions on behalf of the collective of citizens. The latter position suggests that the effects of higher education on environmental policy support are instead channeled through the impact on civic norms.

Traditionally, democratic civic norms refer to civic prescriptions such as the recognition of rule of law, active exercise of the right to vote and the maintenance of political vigilance (Benn 1979; Knack 1992). As of late, studies aimed at better grasping the nature of modern-day collective action problems have done so primarily by focusing on another type of civic norm, namely various expressions of trust. This is understandable, because high levels of trust, both in other people's voluntary compliance with policy initiatives (i.e., generalized trust), in the 
political-administrative system responsible for implementing, surveying, and enforcing policy (i.e., institutional trust), and in the democratically elected representatives responsible for making collective decisions (i.e., political trust), are suggested to impact a number of societal processes, including the support of and compliance with political decisions (Hetherington 1998; Braithwaite and Levi 1998). There are, for example, good reasons to anticipate that a large percentage of individuals will refrain from cooperative behavior or fail to support policies, unless they perceive a reasonable chance of cooperative success or collective efficacy (Lubell et al. 2007). As the outcomes of most environmental policy instruments are dependent on both community and elite efforts, perceptions of cooperative success thus depend on the level of trust in the intentions and capacity of these actors to perform the necessary tasks. Let us expand on this topic.

First, political and institutional trust, or trust in the democratic system, becomes decisive for policy support because the successful implementation of a policy instrument is clearly dependent on both the ambition and ability of political actors and institutions to monitor and enforce compliance, to create incentives for behavioral change, and to present viable alternatives to the public (Devos et al. 2002; Lubell et al. 2007). Most basically, theories on political legitimacy argue that confidence in the political authority's ability to generate the best outputs possible also implies a prima facie support of the political decision made (Matti 2009). Thus, unless people trust the competence of both political decision-makers and political institutions to understand the problem at hand and know what is required for amending it, they will be prone neither to support policy measures nor to comply with them.

Second, trust in political-administrative actors and institutions reflects views on the political government's ability to handle demands for reciprocity. The possibility for governmental coercion to increase predictability of human interaction and thereby eradicate the free-rider problem is intimately connected to a belief in the system's ability to simultaneously implement effective monitoring and enforcement of rule violation, so as to increase both the effectiveness and fairness of these measures (Matti 2009; Harring 2016). A related approach focuses more specifically on the effects of institutional trust on public support for environmental taxes, which can be conceptualized as coercive and demanding policies, in the sense that taxes put a cost on individuals' consumption of certain goods. For example, with regard to support for environmental taxes, several studies (Hammar and Jagers 2006, Harring and Jagers 2013; Dresner et al. 2006; Kallbekken and Sælen 2011; Kallbekken et al. 2013) find that lack of trust in government, and in particular in the government's use of the revenues generated from the taxes, is a key explanatory factor for low levels of public support for such policy instruments. They further suggest that the significance of institutional trust might explain why earmarking revenues, ensuring a fair and proper recycling of public funds, have been found to increase the support for new taxes.

Third, similar to the way social norms serve as a compass indicating how we ought to behave, beliefs about others' intentions to comply also affect personal attitudes towards political decisions and policy instruments (Biel and Thøgersen 2007). Of particular interest is the conclusion by, among others, Ostrom (2005) and Torgler (2003) that many individuals are "conditional cooperators," ready to engage in collective action only to the extent they perceive that others are willing to do the same. This type of reciprocal behavior is thus dependent on the judgment of whether or not other people are reliable. In small-scale settings, characterized by regular interaction and face-to-face communication, previous experience and reputation guide expectations of reciprocity. In large-scale situations, however, the extent to which other people are believed to cooperate is instead based on estimated trustworthiness, 
where high levels of interpersonal trust increase personal willingness to cooperate (cf. Sønderskov 2011). In guiding policy support, however, social trust is expected to work in slightly different ways. On the one hand, distrust in others' predisposition for voluntary behavioral change can be expected to drive general support for the introduction of policy measures mandating change or compensating for defective behavior, particularly if the policy problem is perceived as highly pressing. Conversely, a strong belief in others' voluntary cooperation eradicates the need for third-party involvement to govern behavior and is thus expected to decrease support for policy measures. On the other hand, low levels of interpersonal trust also negatively affect evaluations of a policy measure's effectiveness and fairness and can therefore reduce support for a particular measure if it is perceived as too easy for freeriders to evade (Harring and Jagers 2013).

Based on these three lines of reasoning, we can thus expect a link between civic norms and individuals' propensity to accept policy measures imposed on them. What remains to be explored is if education is also associated with this link, as suggested by, for example, studies focusing on the civic value-promoting effects of social science education (Brady et al. 1995; Lewis-Beck et al. 2009; Pascarella and Terenzini 1991).

H3: Higher education affects environmental policy support indirectly through civic norms. H4: Civic norms affect environmental policy support via acceptance of political steering.

In sum, it seems that there are ample reasons to expect a direct effect on support for environmental policy measures, but it is also plausible that this effect is indirect and occurs through the development of personal norms. Furthermore, we have theorized that these indirect effects can materialize in two different ways: first, a more general political direction, targeting the way we conceive the political-administrative system and our fellow citizens; and second, a more environmentally specific direction targeting our role and responsibility for the environment. As we see it, these two norm-changing effects may constitute the mechanisms by which higher education indirectly affects the level of support for environmental policy measures. These three direct and indirect links are captured in Fig. 1. Arrow $a$ captures the direct effect between education and policy support, arrow $b$ shows the indirect effect on policy support via pro-environmental norms, and arrow $c$ represents the indirect general political effect via civic norms and governmental acceptance.

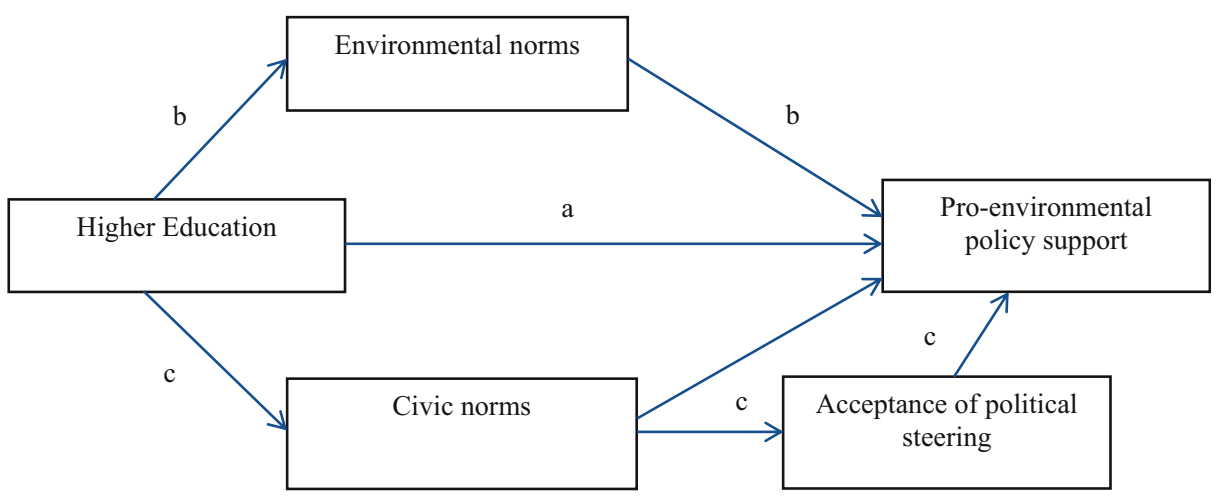

Fig. 1 Proposed connections between higher education and pro-environmental policy support 


\section{Method and material}

\section{Material}

In order to test our hypotheses, we make use of a unique data set, based upon survey responses from Swedish college students at seven Swedish universities during two semesters of undergraduate studies. It is a three-wave panel where the first collection of data was conducted during the first weeks of the semester (August/September 2014), the second during the last weeks of the semester (December/January 2014), and the third during the last weeks of the second semester (May/June 2015). The questionnaire contained a number of different sections and took approximately $15 \mathrm{~min}$ to complete. It was made clear that participation was completely voluntary and those who responded were rewarded with a free movie ticket. We included three different student categories: economics, law, and political science.

During the first wave, $N=1801$ students participated; this number decreased to $N=1366$ during the second wave and $N=813$ in the third wave. Out of these, we were able to match 882 students between the first and the second wave and 388 between the first and the third wave. ${ }^{1}$ There are a number of reasons why we could not match more respondents. First, a substantial number of students dropped out or changed courses during their first weeks. Second, the lectures are seldom compulsory; consequently, a number of students who attended the lecture during the first wave did not attend class in the second wave. Furthermore, undergraduate economics and political science students often take courses in other disciplines the second semester, while the law students do not. Therefore, most of the students that we matched between wave 1 and wave 3 were law students. To estimate change in our main dependent variable, we also made use of a control group from the Citizen Panel provided by LORE (Laboratory of Opinion Research, see www.lore.gu.se) at the University of Gothenburg, ${ }^{2}$ with 916 respondents in both waves. The control group received the question through a web-based survey during the same period.

\section{Dependent and independent variables}

In the surveys, our main dependent variable environmental policy support is captured by three different survey items: "I could support an increase in the carbon tax on car fuels (gasoline, diesel, fossil gas)" (strongly agree to strongly disagree); "I could support political proposals on an aviation carbon tax (kerosene)" (strongly agree to strongly disagree); and "Impose consumption taxes on polluting consumption" (very good suggestion to very bad suggestion). ${ }^{3}$ The constructed index has a good reliability with a Cronbach's $\alpha$ of $.85 .^{4}$ There are several different types of environmental policy instruments. As mentioned above, we focus on taxes as a typical example of a coercive policy tool that demands individual sacrifices, either in terms of behavioral changes or higher monetary costs, by the individuals targeted by the policy.

In order to capture pro-environmental norms, we make use of seven question items: "There is no point for me to do what I can for the environment unless others do too", "As long as all

\footnotetext{
${ }^{1}$ The matching was made through the students' parents' surnames. We have made a solid check, and this matching technique has worked very well.

${ }^{2}$ For more information, see www.lore.gu.se. The respondents in the Citizen Panel are both self-recruited and based on a random population.

${ }^{3}$ The third one is based on a battery of questions where the students are asked to rate several propositions.

${ }^{4}$ Wave 1
} 
laws and regulations are adhered to, there is no reason for Swedish consumers to be concerned about possible environmental damage in other countries", "My own lifestyle has contributed to the current environmental problems", "I am co-responsible for protecting the world's environment", "Ordinary citizens and not just authorities and decision-makers carry a great deal of responsibility for the environment", "I have no personal responsibility to protect the environment", and "I could forgo holiday air travel to reduce emissions of greenhouse gases" $(\alpha=.73)$.

The same or similar questions have been used to capture pro-environmental norms before, which scholars applying the Value-Belief-Norm Theory often described as tapping into the extent to which an individual feels an ascribed (personal) responsibility for both causing and amending the negative environmental situation.

In order to capture civic norms, we make use of questions both capturing trust in political authorities and trust in fellow citizens. The first asks respondents about their level of trust in Swedish authorities: a great deal of trust (1) to very little trust (5) (reversed). Second, trust in fellow citizens is captured by two statements: "Generally speaking, would you say that most people can be trusted, or that you can't be too careful in dealing with people?"5 And, "Generally speaking, do you think that most people would try to take advantage of you if they got the chance, or would they try to be fair?"6

As described above, the link from education to acceptance is argued to operate through an acceptance of government intervention in general. In order to capture attitudes towards political steering, we use two questions: "It is good that politicians and authorities try to influence the behavior of citizens in various ways" and "Politicians and authorities should not try to influence the behavior of citizens" (reversed). These questions were measured on a fivepoint scale from "completely agree" to "completely disagree" (Cronbach's $\alpha .71$ ).

\section{Controls}

We also include controls for the students' subjective placements on the ideological left/right dimension ("It is sometimes said that political opinions can be placed on a left-right scale. Where would you place yourself on such a scale?") using a five-point scale running from "clearly to the left" to "clearly to the right." Individuals on the right of the political spectrum are often more hostile towards market interventions in general, and several studies have shown that compared to individuals on the left, individuals leaning to the right are less likely to express environmental support (Dunlap et al. 2001; for critique, see Harring and Sohlberg 2017; Fairbrother 2016). We also include gender in our analysis, as gender has been argued to affect environmental support (Dunlap et al. 2000; Stern et al. 1993).

\section{Methods}

We use structural equation modeling (SEM) in order to test our hypotheses, since we are interested in the mediating effects of civic norms and environmental norms on environmental policy support (Fig. 2). Furthermore, SEM has the advantage that it can be applied to longitudinal data to capture the stability and change in explanatory variables and the mediating effects of our constructs on our main dependent variable (Little 2013).

\footnotetext{
5 Answer categories: "You cannot be too careful" (1) to "Most people can be trusted" (5).

${ }^{6}$ Answer categories: "Most people would try to take an advantage" (1) to "Most people try to be fair" (5).
} 


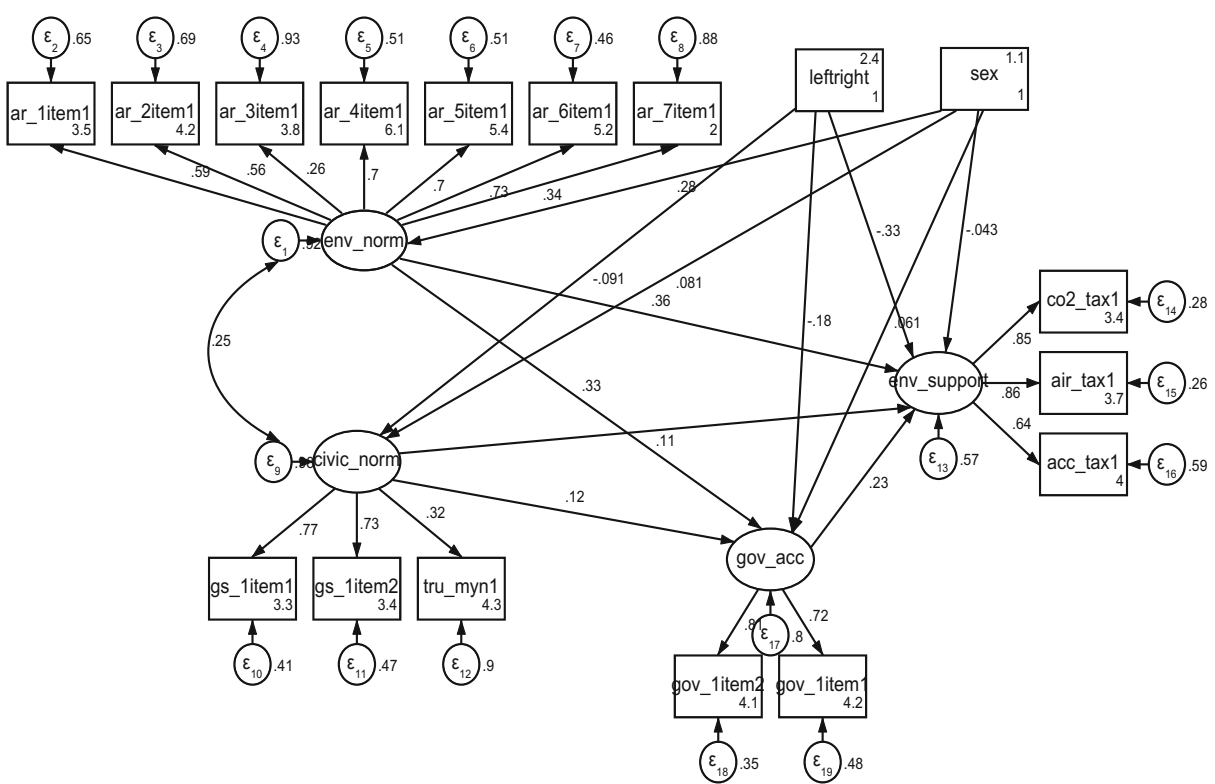

Fig. 2 Structural equation model - first wave. Comments: $(N=1701)$. CFI $=.87$, RMSEA $=.08$. Standardized coefficients

\section{Results}

In order to analyze our data, the first step is to see whether there are any substantial changes in the important variables across the time period that we investigate. Table 1 shows a paired sample $t$ test of the mean values among the students (and among the control group for those variables where we have survey measures) at waves 1, 2, and 3. For our main dependent variable, environmental policy support, we see that there is a small but significant change in the student group between the first and the second waves, but no significant change between waves 1 and 3 . There is no change in the control group. ${ }^{7}$

Studying the mean value change in environmental protection norms, we see a decrease among students, both comparing students participating in wave 1 and wave 2, and students participating in wave 1 and wave 3 . Hence, we conclude that on the group level, students (in Sweden) do not experience any stronger personal responsibility for protecting the environment after taking courses in economics, law, and political science. This finding has been confirmed in previous studies using the data on the first and second wave [Harring, Lundholm and Torbjörnsson (2017) Harring and Jagers (2018)]. This is also in line with some previous research reporting a tendency for college students to gradually generate more cynical perspectives on social dilemma situations, and a sense that their potential to contribute is rather low (Newman and Fernandes 2015).

We find no significant change in civic norms, as operationalized through levels of generalized, political, and institutional trust; the tendency is a decrease rather than an increase.

In order to estimate whether civic norms and pro-environmental norms have any explanatory power on policy support, we use a SEM framework.

\footnotetext{
${ }^{7}$ It is worth noticing that the control group actually scores higher than the student group; however, there is no change.
} 
Table 1 Mean value comparisons wave 1 and wave 2

\begin{tabular}{|c|c|c|c|c|}
\hline & Wave 1 & Wave 2 & Difference & $N$ \\
\hline Change in pro-environmental policy support & 3.51 & 3.57 & $.05^{*}$ & 865 \\
\hline Change in pro-environmental policy support - control group & 3.77 & 3.77 & .00 & 843 \\
\hline Change in environmental norm & 3.93 & 3.88 & $-.05 * * *$ & 859 \\
\hline Change in civic norm & 3.37 & 3.35 & -.02 & 867 \\
\hline \multirow{2}{*}{ Change in government intervention acceptance } & 3.68 & 3.68 & .00 & 866 \\
\hline & Wave 1 & Wave 3 & Difference & $N$ \\
\hline Change in pro-environmental policy support & 3.47 & 3.48 & .01 & 309 \\
\hline Change in pro-environmental policy support - control group & 3.81 & 3.83 & .02 & 734 \\
\hline Change in environmental norm & 3.94 & 3.86 & $-.08 * * *$ & 305 \\
\hline Change in civic norm & 3.34 & 3.34 & .00 & 306 \\
\hline Change in government intervention acceptance & 3.66 & 3.72 & .06 & 306 \\
\hline
\end{tabular}

$* * * p<0.001 ; * p<0.05$

In the first model, we analyze explanations behind policy acceptance. We see a clear effect of environmental norms (.36) on policy acceptance, as well as that the effect of civic norms on policy acceptance is mediated through a positive attitude towards government steering. Studying the other variables, we find an effect of self-placement on the left-right scale (-.33): Students who position themselves to the left on the political spectrum are much more likely to accept the tested policy instrument.

Furthermore, we find that environmental norms are clearly related to the acceptance of government steering (.33). It is not perfectly clear why people who accept a lot of personal responsibility are more willing to accept government steering in general, but acceptance of personal environmental responsibility norms and acceptance of authority are related. Acceptance of authority can at least be thought of as an antipode of free-riding norms. People who do not feel moral or personal norms when it comes to the protection of the environment are not very likely to accept steering, or government authorities telling them how to act or using force to make them behave in a certain manner.

Moving on to the longitudinal SEM, we find quite strong autoregressive effects in our construct between wave 1 and wave 2, and also wave 1 and wave 3 . The intercorrelations between the latent variables between the waves are high, which was more or less expected when we saw that the mean score changes between the time points were low. The effect of civic values at $\mathrm{t} 1$ on civic values at $\mathrm{t} 2$ is strong $(.86, p<.000)$ and so is the effect of acceptance at $\mathrm{t} 1$ on acceptance at $\mathrm{t} 2(.83$, $p<.000)$, and the effect of environmental values at $\mathrm{t} 1$ on environmental values at $\mathrm{t} 2(.84, p<.000)$. Hence, as the acceptance is very stable between $\mathrm{t} 1$ and $\mathrm{t} 2$, not much variance can be explained by the change in other factors. This is also what we find between $\mathrm{t} 1$ and $\mathrm{t} 3$ (Table 2).

\section{Discussion}

In this article, we are concerned with exploring the puzzling relationship between (higher) education and acceptance of environmental policy measures. We do so by focusing on two parallel causal links presented as the environmental norm hypothesis $\left(\mathrm{H}_{2}\right)$ and the civic norm hypotheses $\left(\mathrm{H}_{3}, \mathrm{H}_{4}\right)$, respectively. By analyzing changes in norms and attitudes among university students and comparing these changes to a control group, we initially find that the group of university students does become more accepting of environmental policy instruments during the semester, whereas no significant changes in policy attitudes are detected 
Table 2 Paths and covariances for the longitudinal structural equation model

\begin{tabular}{|c|c|c|c|}
\hline & Std est. & Std. err. & $P$ \\
\hline \multicolumn{4}{|l|}{ Paths } \\
\hline Civic norm (Time 1) $\rightarrow$ Civic norm (Time 2 ) & .86 & .03 & .000 \\
\hline Civic norm (Time 1) $\rightarrow$ Env. Pol. Support (Time 2) & .05 & .03 & .126 \\
\hline Env. Norm (Time 1) $\rightarrow$ Env. Pol. Support (Time 2) & .19 & .03 & .000 \\
\hline Env. Pol. Support (Time 1) $\rightarrow$ Env. Pol. Support (Time 2) & .83 & .02 & .000 \\
\hline Civic norm (Time 1) $\rightarrow$ Env. Norm (Time 2) & .14 & .03 & .002 \\
\hline Env. Norm (Time 1) $\rightarrow$ Env. Norm (Time 2) & .84 & .02 & .000 \\
\hline \multicolumn{4}{|l|}{ Covariances } \\
\hline Civic norm (Time 2) $\longleftrightarrow$ Env. Pol. Support (Time 2) & .22 & .09 & .010 \\
\hline Civic norm (Time 2 ) $\longleftrightarrow$ Env. Norm (Time 2) & .25 & .10 & .009 \\
\hline Env. Pol. Support (Time 2) $\longleftrightarrow$ Env. Norm (Time 2) & .31 & .07 & .000 \\
\hline Civic norm (Time 1) $\longleftrightarrow$ Env. Norm (Time 2) & .15 & .05 & .002 \\
\hline Civic norm (Time 1) $\longrightarrow$ Env. Pol. Support (Time 1) & .25 & .05 & .000 \\
\hline \multicolumn{4}{|l|}{ Paths } \\
\hline Civic norm (Time 1 ) $\rightarrow$ Civic norm (Time 3 ) & .77 & .05 & .000 \\
\hline Civic norm (Time 1) $\rightarrow$ Env. Pol. Support (Time 3) & .00 & .05 & .964 \\
\hline Env. Norm (Time 1) $\rightarrow$ Env. Pol. Support (Time 3) & .05 & .05 & .275 \\
\hline Env. Pol. Support (Time 1) $\rightarrow$ Env. Pol. Support (Time 3) & .86 & .03 & .000 \\
\hline Civic norm (Time 1) $\rightarrow$ Env. Norm (Time 3) & .24 & .06 & .000 \\
\hline Env. Norm (Time 1) $\rightarrow$ Env. Norm (Time 3 ) & .74 & .04 & .000 \\
\hline \multicolumn{4}{|l|}{ Covariances } \\
\hline Civic norm (Time 3) $\longleftrightarrow$ Env. Pol. Support (Time 3) & .23 & .11 & .037 \\
\hline Civic norm (Time 2) $\longleftrightarrow$ Env. Norm (Time 2) & .15 & .12 & .208 \\
\hline Env. Pol. Support (Time 3) $\longleftrightarrow$ Env. Norm (Time 3) & .49 & .10 & .000 \\
\hline Civic norm (Time 1) $\longleftrightarrow$ Env. Norm (Time 3) & .15 & .08 & .061 \\
\hline Civic norm (Time 1) $\longleftrightarrow$ Env. Pol. Support (Time 3) & .28 & .08 & .000 \\
\hline
\end{tabular}

in the control group during the same time period, and there is no change in the group of students that we could match over two semesters. This result provides weak support for our initial hypothesis $\left(\mathrm{H}_{1}\right)$, which states that there is a direct effect of higher education on environmental policy support. Furthermore, we also find that environmental norms and civic norms (e.g., institutional trust) are important drivers for environmental policy support. When testing our other hypotheses, however, we do not find that changes in environmental and civic norms between our two waves of data collection can explain the changes in environmental policy support for the same period of time. Thus, we cannot confirm $\mathrm{H}_{2}$ and $\mathrm{H}_{3}$, proposing an indirect effect of higher education channeled through civic and environmental norms. We do find that changes in acceptance of government steering have an effect on environmental policy support at an individual level $\left(\mathrm{H}_{4}\right)$.

\section{Conclusions}

To our knowledge, this is one of only a few studies attempting to disentangle the causal mechanisms of higher education's effect on environmental policy support. Compared to our control group, we find that the group of university students does become more accepting of environmental policy instruments during the semester, which provides some support for our assumption that there is a direct effect of higher education on environmental policy support. We do not find that changes in environmental and civic norms between our two waves of data 
collection can explain the changes in policy support for the same period of time. However, we find that changes in acceptance of government steering have an effect on environmental policy support on an individual level.

Future research can extend the findings of this study in several ways. It should firstly be noted that this article uses support for environmental taxes as the dependent variable. While this is an important and widely debated policy measure, meriting attention to the prospect for public support, several recent studies have argued that it is important to distinguish between different types of environmental policy measures when gauging support. For example, pull instruments increasing the attractiveness of pro-environmental behavior generally gain more support than push instruments aimed at exacerbating the negative impact of a behavioral choice, and suggestions for making new environment-friendly alternatives available to the public are received more positively than targeting a reduction of established practices (cf. Jagers and Matti 2010; Steg et al. 2005). Furthermore, trust generally has a positive effect on economic incentives, but not necessarily on command-and-control types of policies (Harring 2016). Research on this topic should therefore include a number of policy measures, allowing them to vary between different designs, in order to analyze how much and in what direction different norms trigger responses to different types of policy measures. Future studies can also better explore the role of social science knowledge on policy support (cf. Harring et al. 2017). Finally, since the study has been conducted in only one country, Sweden, which is known for having an exceptionally pro-environmental oriented population, it is also important to replicate the study in other contexts. This should be done not only to see if the results are unique to Sweden but also to get a better grip of the magnitude of the effects found in this study, e.g., are they weaker or stronger among university students in other countries?

Acknowledgments This work was supported by the Swedish Research Council within the project Climate Change Challenge [721-2011-5991].

Open Access This article is distributed under the terms of the Creative Commons Attribution 4.0 International License (http:/creativecommons.org/licenses/by/4.0/), which permits unrestricted use, distribution, and reproduction in any medium, provided you give appropriate credit to the original author(s) and the source, provide a link to the Creative Commons license, and indicate if changes were made.

\section{References}

Arnon, S., Orion, N., \& Carmi, N. (2015). Environmental literacy components and their promotion by institutions of higher education: An Israeli case study. Environmental Education Research, 21, 1029-1055.

Beetham, D. (1991). The legitimation of power. Basingstoke: Macmillian.

Benn, S. (1979). The problematic rationality of political participation. In P. Laslett \& J. Fishkin (Eds.), Philosophy, politics, and society. New Haven: Yale University Press.

Biel, A., \& Thøgersen, J. (2007). Activation of social norms in social dilemmas: A review of the evidence and reflections on the implications for environmental behaviour. Journal of Economic Psychology, 28(1), 93112 .

Brady, H. E., Verba, S., \& Schlozman, K. L. (1995). Beyond SES: A resource model of political participation. The American Political Science Review, 89(2), 271-294.

Braithwaite, V., \& Levi, M. (1998). Trust and governance. New York: Russell Sage Foundation.

Brand, J. E. (2010). Civic returns to higher education: A note on heterogeneous effects. Social Forces, 89(2), $417-433$.

Bryant, A. N., Gayles, J. G., \& Davis, H. A. (2012). The relationship between civic behavior and civic values: A conceptual model. Research in Higher Education, 53(1), 76-93. 
Cotton, D. R. E., \& Alcock, I. (2013). Commitment to environmental sustainability in the UK student population. Studies in Higher Education, 38(10), 1457-1471.

De Groot, J. I., \& Steg, L. (2008). Value orientations to explain beliefs related to environmental significant behavior: How to measure egoistic, altruistic and biospheric value orientation. Environment and Behavior, 40(3), 330-354.

Dee, T. S. (2004). Are there civic returns to education? Journal of Public Economics, 88(9-10), 1697-1720.

Devos, T., Spini, D., \& Schwartz, S. H. (2002). Conflicts among human values and trust in institutions. The British Journal of Social Psychology, 41(4), 481-449.

Dresner, S., Dunne, L., Clinch, P., \& Beuermann, C. (2006). Social and political responses to ecological tax reform in Europe: An introduction to the special issue. Energy Policy, 34(8), 895-904.

Dunlap, R. E., Van Liere, K. D., Mertig, A. G., \& Jones, R. E. (2000). Measuring endorsement of the new ecological paradigm: A revised NEP scale. Journal of Social Issues, 56(3), 425-442.

Dunlap, R. E., Xiao, C., \& McCright, A. M. (2001). Politics and environment in America: Partisan and ideological cleavages in public support for environmentalism. Environmental Politics, 10(4), $23-48$.

Fairbrother, M. (2016). Trust and public support for environmental protection in diverse national contexts. Sociological Science, 3, 359-382.

Galston, W. A. (2001). Political knowledge, political engagement, and civic education. Annual Review of Political Science, 4(1), 217-234.

Hammar, H., \& Jagers, S. C. (2006). Can trust in politicians explain individuals' support for climate policy? The case of CO2 tax. Climate Policy, 5(6), 613-625.

Hardin, G. (1968). The Tragedy of the Commons. Science, 162, 1243-1248.

Harraway, J., Broughton-Ansin, F., Deaker, L., Jowett, T., \& Shephard, K. (2012). Exploring the use of the revised new ecological paradigm scale (NEP) to monitor the development of students' ecological worldviews. The Journal of Environmental Education, 43, 177-191.

Harring, N. (2016). Reward or punish? Understanding preferences toward economic or regulatory instruments in a cross-national perspective. Political Studies, 64(3), 573-592.

Harring, N., \& Jagers, S. C. (2013). Should We trust in Values? Explaining Public Support for Pro-Environmental Taxes. Sustainability, 5(1), 210-227.

Harring, N., Davies, P., \& Lundholm, C. (2017). Learning economics and attitudes to market solutions to environmental problems. Education Sciences, 7(1), 36.

Harring, N., Lundholm, C., \& Torbjörnsson, T. (2017). The Effects of Higher Education in Economics, Law and Political Science on Perceptions of Responsibility and Sustainability. In W. Leal Filho, L. Brandli, P. Castro, \& J. Newman (Eds.), Handbook of Theory and Practice of Sustainable Development in Higher Education : Volume 1 (pp. 159-170). Cham: Springer International Publishing.

Harring, N., \& Sohlberg, J. (2017). The varying effects of left-right ideology on support for the environment: Evidence from a Swedish survey experiment. Environmental Politics, 26(2).

Harring, N., \& Jagers, S. C. (2018). Why do people accept environmental policies? The prospects of higher education and changes in norms, beliefs and policy preferences. Environmental Education Research, 24(6), 791-806.

Hetherington, M. J. (1998). The political relevance of political trust. The American Political Science Review, 92(4), 791-808.

Inglehart, R. (1990). Culture shift in advanced industrial society. Princeton, N.J: Princeton University Press.

Jagers, S. C., Martinsson, J., \& Matti, S. (2014). Ecological citizenship: A driver of pro-environmental behaviour? Politics, 23(3), 434 453.

Jagers, S. C., \& Matti, S. (2010). Ecological citizens: Identifying values and beliefs that support individual environmental responsibility among swedes. Sustainability, 2(4), 1055.

Jones, R. E., \& Dunlap, R. E. (1992). The social bases of environmental concerns: Have they changed over time? Rural Sociology, 57(1), 28-47.

Kallbekken, S., Garcia, J. H., \& Korneliussen, K. (2013). Determinants of public support for transport taxes. Transportation Research Part A: Policy and Practice, 58(0), 67-78.

Kallbekken, S., \& Sælen, H. (2011). Public acceptance for environmental taxes: Self-interest, environmental and distributional concerns. Energy Policy, 39(5), 2966-2973.

Knack, S. (1992). Civic norms, social sanctions and voting turnout. World Bank, MPRA Paper No. 28080. http://mpra.ub.uni-muenchen.de/28080/. Accessed 14 January 2011.

Kvaløy, B., Finseraas, H., \& Listhaug, O. (2012). The publics' concern for global warming: A cross-national study of 47 countries. Journal of Peace Research, 49, 11-22.

Lewis-Beck, M. S., Jacoby, W. G., Norpoth, H., \& Weisberg, H. F. (2009). The American voter revisited. Ann Arbor: University of Michigan Press.

Little, T. D. (2013). Longitudinal structural equation modeling. New York: Guilford Press. 
Lubell, M., Zahran, S., \& Vedlitz, A. (2007). Collective action and citizen responses to global warming. Political Behavior, 29(3), 391-413.

Mansbridge, J. (2014). The role of the state in governing the commons. Environmental Science and Policy, 36(0), $8-10$.

March, J. G., \& Olsen, J. P. (2004). The logic of appropriateness. In M. Moran, M. Rein, \& R. E. Goodin (Eds.), The Oxford handbook of public policy. Oxford: Oxford University Press.

Matti, S. (2009). Exploring public policy legitimacy: A study of belief-system correspondence in Swedish environmental policy. (Doctoral thesis), Luleå University of Technology, Luleå.

McCowan, T. (2012). Opening spaces for citizenship in higher education: Three initiatives in English universities. Studies in Higher Education, 37(1), 51-67.

Milligan, K., Moretti, E., \& Oreopoulos, P. (2004). Does education improve citizenship? Evidence from the United States and the United Kingdom. Journal of Public Economics, 88(9-10), 1667-1695.

Newman, T. P., \& Fernandes, R. (2015). A re-assessment of factors associated with environmental concern and behavior using the 2010 general social survey. Environmental Education Research, 1-23.

Nie, N. H., Junn, J., \& Stehlik-Barry, K. (1996). Education and democratic citizenship in America. Chicago: University of Chicago Press.

Nordlund, A., \& Garvill, J. (2002). Value structures behind proenvironmental behaviors. Environment and Behavior, 34(6), 740-756.

O'Connor, R. E., Bard, R. J., \& Fisher, A. (1999). Risk perceptions, general environmental beliefs, and willingness to address climate change. Risk Analysis, 19, 461-471.

Olson, M. (1965). The logic of collective action: Public goods and the theory of groups. Cambridge, MA: Harvard University Press.

Ostrom, E. (2005). Understanding institutional diversity. Princeton, N.J: Princeton University Press.

Pascarella, E. T., \& Terenzini, P. T. (1991). How college affects students. San Francisco: Jossey-Bass.

Paterson, L. (2009). Civic values and the subject matter of educational courses. Oxford Review of Education, 35(1), 81-98.

Persson, M. (2013). Education and political participation. British Journal of Political Science, 45(3), 689-703.

Sagoff, M. (1988). The Economy of the Earth. Cambridge: Cambridge University Press.

Schwartz, S. H. (1977). Normative influences on altruism. In L. Berkowitz (Ed.), Advances in experimental social psychology (Vol. 10, pp. 221-279). New York: Academic Press.

Shephard, K. (2008). Higher education for sustainability: Seeking affective learning outcomes. International Journal of Sustainability in Higher Education, 9, 87-98.

Shephard, K., Harraway, J., Jowett, T., Lovelock, B., Skeaff, S., Slooten, L., Strack, M., \& Furnari, M. (2015). Longitudinal analysis of the environmental attitudes of university students. Environmental Education Research, 21(6), 805-820.

Sønderskov, K. M. (2011). Explaining large-N cooperation: Generalized social trust and the social exchange heuristic. Rationality and Society, 23(1), 51-74.

Soroka, S. N., \& Wlezien, C. (2010). Degrees of democracy: Politics, public opinion, and policy: Cambridge University Press.

Steg, L., Drejjerink, L., \& Abrahamse, W. (2005). Factors influencing the acceptability of energy policies: A test of VBN theory. Journal of Environmental Psychology, 25(4), 415-425.

Steg, L., \& Vlek, C. (2009). Encouraging pro-environmental behaviour: An integrative review and research agenda. Journal of Environmental Psychology, 29(3), 309-317.

Stern, P. C., Dietz, T., \& Black, J. S. (1995). Support for environmental protection: The role of moral norms. Population \& Environment, 8(3), 204-222.

Stern, P. C., Dietz, T., \& Kalof, L. (1993). Value orientations, gender and environmental concern. Environment and Behavior, 25(5), 322-348.

Stubager, R. (2008). Education effects on authoritarian-libertarian values: A question of socialization. The British Journal of Sociology, 59(2), 327-350.

Torgler, B. (2003). Tax morale, rule governed behavior and trust. Constitutional Political Economy, 14(2), 119140.

United Nations. (2005). United Nations decade of education for sustainable development, G.A. Resolution 59/ 237. New York NY: United Nations General Assembly 24 February, 2005.

Van de Werfhorst, H. G., \& de Graaf, N. D. (2004). The sources of political orientations in post-industrial society: Social class and education revisited. The British Journal of Sociology, 55(2), 211-235.

Van Liere, K. D., \& Dunlap, R. E. (1980). The social bases of environmental concerns: A review of hypotheses, explanations and empirical evidence. The Public Opinion Quarterly, 44(2), 181-197. 
Vaske, J. J., Donnelly, M. P., Williams, D. R., \& Jonker, S. (2001). Demographic influences on environmental value orientations and normative beliefs about national forest management. Society and Natural Resources, $14,761-776$.

Wallner, J. (2008). Legitimacy and Public Policy: Seeing Beyond Effectiveness, Efficiency, and Performance. Policy Studies Journal, 36(3), 421-443.

Zahran, S., Brody, S. D., Grover, H., \& Vedlitz, A. (2006). Climate change vulnerability and policy support. Society \& Natural Resources, 19, 771-789.

Publisher's note Springer Nature remains neutral with regard to jurisdictional claims in published maps and institutional affiliations. 